Türk Coğrafya Dergisi
Turkish Geographical Review
Bww.tcd.org.tr
BasIlI ISSN 1302-5856

\title{
Havalimanlarında kalkışöncesi, acil durumlarda, yardım alınabilecek en uygun lokasyonun Weber problemine uyarlanarak belirlenmesi
}

\author{
Determining the most suitable location for receiving support in emergency cases prior to takeoff \\ at airports by applying the Weber problem
}

\author{
Emre Demir*a (1) \\ ${ }^{a}$ Antalya Bilim Üniversitesi, Mühendislik Fakültesi, Inşaat Mühendisliği Bölümü, Antalya.
}

\section{BILGI / INFO}

Geliş/Received: 17.02 .2018

Kabul/Accepted: 30.03 .2018

Anahtar Kelimeler:

Lokasyon analizi

Havalimanı

Weber problemi

Weizsfeld yöntemi

\section{Keywords:}

Location analysis

Airport

Weber problem

Weizsfeld method

*Sorumlu yazar/Corresponding author:

(E. Demir) emre.demir@antalya.edu.tr

DOI: $19.17211 /$ tcd.396278

\section{Atff/Citation:}

Demir, E. (2018). Havalimanlarında kalkış öncesi, acil durumlarda, yardım alınabilecek en uygun lokasyonun Weber problemine uyarlanarak belirlenmesi. Türk Coğrafya Dergisi (70), 81-85. DOI:19.17211/tcd.396278.

\begin{abstract}
ÖZ / ABSTRACT
Türkiye'de son yıllarda sivil havacılık hızlı bir şekilde gelişmiştir ve bu ivme artarak devam etmektedir. Tüm dünyada ve ülkemizde hızla büyüyen sivil havacılık sektörü ve işletmeciliği hemen hemen herkesin kullanımına elverişli olan bir alandır. Sivil havacılığın her geçen gün beraberinde getirdiği sorunlara yönelik çözümler oluşturulması adına birçok akademik araştırma yapılmıştır ve halen yapılmaktadır. Çoğu kez karşılaşılan sorunlardan bir tanesi de acil ve beklenmedik durumlarda bakım ve yedek parça hizmetlerinin başka bir havalimanından tedarik edilmesinin gereğidir. Gerekli olan bakım, onarım veya yedek parça hizmeti çok hızlı bir şekilde tedarik edilmelidir ki havayolu şirketinin zamansal ve dolayısıyla parasal kaybı da en aza inmelidir. Bu makale çalışmasında Türkiye'nin sivil havalimanlarından sağlanan veriler ile birlikte, bahse konu sorunun ülke çözüme kavuşturulması konusunda en kullanılabilir havalimanının sınırları içerisinde tespiti, Weber problemine uyarlanıp Weizsfeld yöntemi kullanılarak çözümlenmiştir. Bu çalışmanın sonucunda, yurtiçinde bu önemli soruna karşılık hizmet verebilecek en uygun lokasyona sahip havalimanına dikkat çekilmiştir. Elde edilen bulgular doğrultusunda, kalkış öncesi uçuş emniyetinin sağlanması, beklenmedik durumların oluşma riski göz önünde bulundurulmalıdır. Bu risk payının gerçekleşmesi durumunda ek maliyetlerin oluşması, zaman kaybı, gecikmelerden kaynaklanan müşteri memnuniyetinin azalması gibi zararların en alt seviyede tutulması için bu makaledeki çalışmanın sonuçları yol gösterici olacaktır. Analizler sonucu belirlenen havalimanının Türkiye çapına servis sağlaması ve acil durumlarda talep edileni karşılaması açısından en kullanılabilir havalimanı olduğu değerlendirilmektedir.
\end{abstract}

In recent years, civil aviation in Turkey has developed rapidly and this developing rate continues. Civil aviation sector and its management which is still advancing in our country and throughout the world are commonly available to be utilized by almost all people. Many academic research has been completed and many are being carried out in order to solve the problems which are brought by the rapid growth of civil aviation. One of the most encountered and important issues is the necessity for supplying maintenance and spare parts in emergency or unforeseen circumstances. The necessary maintenance, repair or spare parts service must be provided very quickly so that the financial loss of the airline company is minimized. In this study, with the help of the data supplied from the civil airports in Turkey, the determination of the most suitable airport in terms of location takes place and the issue is resolved by assigning a domestic airport with the help of the Weber problem and the Weizsfeld method. As a result, in terms of location, the best fit domestic airport which can serve to solve such an important problem is pointed out. In accordance with the findings, in order to provide a safe flight and take the risk of unexpected cases prior to the flight into consideration, this study will be instructive to decrease the losses such as time wasting, decrease of customer satisfaction rates, additional costs once the risk mentioned occurs. The airport, which is the most applicable in terms of location, to provide service to the other airports throughout Turkey is determined according to the analysis.

\section{Giriş}

Tüm dünyada ve ülkemizde hızla büyüyen sektörlerden biri de havacılıktır. Hemen hemen herkesin kullanımına elverişli olan sivil havacılık sektörü, son yıllarda ülkemizde de ivmeli bir şekilde gelişmiştir (SHGM, 2016). Ulaşttrma dalında önemli bir rol oynayan havacılık sektöründe, karayolu, denizyolu, demiryolu gibi ulaştırma dallarında görülen kazalar, havayolunda da görülmektedir. Her ne kadar hatalar zincirinde oluşan bu kazalar en aza indirilmeye çalışılsa da, kaza esnasında can ve mal kaybı üst düzeyde olmaktadır. Havayolu kazalarını düşük oranlara çekmenin önemli yöntemlerinden bir tanesi de uçak yerdeyken beklenmedik bir arıza veya mekanik hata karşısında gereken ehemmiyeti gösterip acilen duruma müdahale etmek- 
tir. Gerekli olan mühendislik hizmeti ve yedek parça çok hızlı bir şekilde tedarik edilmelidir. Ne kadar hızlı bir müdahale olursa, havayolu şirketinin zamansal ve dolayısıyla parasal kaybı da en aza inecektir.

Sivil havacılık ve altyapısı konusunda ülkemiz son yıllarda büyük mesafeler kaydetmiştir. Yeni havalimanları hizmete girerken bununla beraber iç ve dış hatlar sefer sayıları hızlı bir şekilde artmıştır (SHGM, 2016). Bu da havaalanlarına inen ve kalkan uçak sayılarında önemli bir artş̧ yaratmıştır. Bilindiği üzere, her havaalanında bir bakım ünitesi vardır ve uçakların kalkış öncesi durum değerlendirmesini yapmaktadırlar. Uygun görüldüğü takdirde ise sefer gerçekleştirilmektedir. Günümüzün uçakları her ne kadar en ileri seviye teknoloji ürünleri olsalar dahi bazı durumlarda yedek parça ürünleri acilen gerekebilir. Parçanın uçağın bulunduğu havaalanında olmaması durumunda ise, havayolu şirketleri zor duruma düşmekte ve parçanın başka bir havaalanındaki bakım ünitesinden (genellikle büyük bir havaalanından) getirilmesi gerekebilmektedir. İhtiyacın en kısa zamanda tedariki büyük önem teşkil etmektedir. Bu durumlarda ise gerekli hizmetin en kısa sürede ihtiyaç bulunan havaalanına gönderilmesi zaman ve para kaybını en aza indirme açısından çok önemlidir. Ülkemizin her sivil havalimanına bu gibi hizmetleri en kısa sürede sunmanın bir yöntemi ise havalimanlarının lokasyonlarına ve intiyaç oranlarına dikkat ederek bir eniyileme sunmaktır. Eniyileme yöntemleri bu gibi durumlarda çözüm yaratarak havayolu şirketlerinin acil ve beklenmedik olarak ortaya çıkan bakım ve yedek parça hizmetleri konusunda para ve zaman kayıplarını minimum seviyeye çekebilir.

Bu çalışmada Türkiye'nin sivil havalimanlarından sağlanan veriler ile birlikte, acil ve beklenmedik durumlarda bakım ve yedek parça hizmetlerinin başka bir havalimanından tedariki için ülke sınırları içerisinde en kullanılabilir havaalanı tespiti konusu, Weber problemine (Weber, 1929) uyarlanıp Weizsfeld yöntemi (Weizsfeld, 1937) kullanılarak çözümlenmiştir. Bu kapsamda kalkış öncesi uçuş emniyetinin sağlanması için beklenmedik durumların oluşma riski de her daim gözetildiğinden, bu riskin oluşması durumunda zararın en alt seviyede tutulması konusunda bu makaledeki çalışmanın sonuçları yol gösterici olacaktr.

Ülkemizde sivil havacılığın hızla büyümesi, havayolu altyapısının aynı hızda geliştirilmesi gerekliliğini beraberinde getirmektedir. Hızlı büyüyen sektördeki risk sahalarının belirlemek hizmet kalitesini artıracağı gibi havayolu şirketlerinin zararlarını minimuma indirecektir. Ülkemizde havayolu güvenliği, uluslararası ortalamalara bakıldığında geliştirilmesi söz konusu olan bir alandır (Özdoğan vd., 2005; Uçak-Havacılık-Uzay Mühendisliği Meslek Dalı Ana Komisyonu, 2016). Gelişmiş ülkelerin birçoğuna bakıldığında bir milyon kalkış itibariyle ölümlü kaza oranı 0,17 ila 1,36 arasındadır. Ülkemizde ise bu oran 3,60 olarak verilmektedir (Airport Haber, 2017). Bu gibi uluslararası istatistiklere bakılınca uçakların kalkış öncesi acil bakım hizmeti veya acil yedek parça hizmetinin gerekip gerekmediği konusunun önemi bir kez daha anlaşılmaktadır.

\section{Veri ve Yöntem}

\subsection{Coğrafi Verilerin Aktarılması}

Havalimanlarındaki uçak trafiği ve sayıları, Türkiye'de bulunan sivil havaalanlarına göre sıralanmış bir şekilde Devlet Hava
Meydanları İşletmesi (DHMi) internet sitesinde paylaşılmıştır (DHMi, 2017a). Veriler aylara ve yıllara göre kayıt altına alınmış bir biçimdedir. Bu paylaşımlarda havaalanlarını kullanan uçaklar iç hatlar ve dış hatlar olarak iki şekilde gösterilmiştir. Bu çalışmada havaalanlarını kullanan toplam uçaklar ele alınacağından, uçakların iç hatlara veya dış hatlara gelmiş olması bir farklılık yaratmamaktadır. Bu sebepten, spesifik bir havaalanını kullanan iç ve dış hatların toplam uçak sayıları ele alınacaktır.

En güncel verilerin kullanımı ve bundan dolayı da en güncel çözümün ortaya çıkarılması amaçlandığından, son on iki aylık bir süre ele alınacaktır. Bu yüzden 2016 yılının Kasım ayı uçak trafik verilerinden başlayarak 2017 yılının Ekim ayı uçak trafik verilerine kadar olan bölüm incelenecektir. 2016 yılının Kasım ve Aralık ayları ile birlikte 2017 yılının Ocak, Şubat, Mart, Nisan, Mayıs, Haziran, Temmuz, Ağustos, Eylül ve Ekim aylarının havaalanlarına göre uçak kullanım sayısı hakkındaki araşttrma verileri DHMi'nin internet sitesinden indirilmiştir (DHMi, 2017a). Veriler *.pdf formatında olduğu için gerekli işlemlerden geçirilerek *.xlsx formatına eksiksiz aktarılmıştır. Gerekli yazılım fonksiyonların *.xlsx dosyasının her açıldığında uygun bir biçimde Visual Basic programı ile çalışabilmesi için, ${ }^{*}$.xlsx dosyası * .xlsm formatında kaydedilmiştir.

DHMI'nin internet sitesinde sunulan verilere ek olarak, havaalanlarının Türkiye'deki konumlarını belirlemek, yapılacak olan eniyileme işleminde çok büyük bir rol oynamaktadır. Bu sebeple tüm havaalanlarının konumlarını içeren veriler gerekmektedir. DHMi internet sitesinde Türkiye'deki bütün sivil havacılığa hizmet veren havaalanlarının coğrafi koordinatları derece, dakika, saniye cinsinden bulunmaktadır. Yalnızca birkaç havalimanının (örneğin, Sabiha Gökçen, Aydın Çıldır, Eskişehir Anadolu Havalimanı) coğrafi koordinatları Google ${ }^{\circledR}$ internet arama motorundan faydalanarak tespit edilmiştir.

Belirlenen havalimanları koordinatları, havalimanlarının yerkürenin üzerinde olduğu varsayılan ve küresel bir referans sistemi olan coğrafi enlemler ve boylamlara göre olan konumlarıdır. Ancak bu çalışmada yapılan eniyileme işlemlerinde düzleme dayalı veriler kullanılmıştır, çünkü bir düzlem koordinat sisteminin optimizasyon işlemlerinin yapılması daha basit ve uygulanabilirdir. Başka bir deyişle, bütün havalimanlarının konumları yatay bir düzleme aktarılmış ve eniyileme işlemi yapılmıştır.

Düzleme dayalı dünya haritalarında genel olarak kabul edilen ve kullanılan Mercator projeksiyonu yapılacak olan işlemler için seçilmiştir. Dünyanın geoit (üstlerden basık, yanlardan şişkin) halinden dolayı, küresel konumlandırmadan gelen koordinatları Mercator projeksiyonuna çevirmek için uygun bir geometrik konstrüksiyon olmamasına rağmen, aşağıda verilen değişkenler ve bağıntılar dikdörtgen biçimli ( $X$ ve $Y$ ) koordinatları yazma amaçlı kullanılmaktadır (Snyder, 1987).

$$
x=\pi R\left(\lambda^{\circ}-\lambda_{0}^{\circ}\right) / 180^{\circ}
$$

$$
y=R \ln \tan \left(45^{\circ}+\Phi^{\circ} / 2\right)
$$

x: Dikdörtgenel koordinat sisteminde yatay düzlemdeki konum y: Dikdörtgenel koordinat sisteminde düşey düzlemdeki konum

R: Çizilen harita ölçeğinde kullanılan kürenin yarıçapı

$\lambda^{\circ}$ : Derece cinsinden enlem değeri

$\lambda_{0}{ }^{\circ}$ : Derece cinsinden sıfir enlem (ekvator) değeri

$\Phi^{\circ}$ : Derece cinsinden boylam değeri 
Havalimanlarının koordinatları (1) ve (2) numaralı denklemlere göre diktörtgenel düzlem koordinat sistemine çevrilerek lokasyon analizi yapılması için gerekli veriler elde edilmiştir. Bu çaIışmadaki metodoloji Weiszfeld yönteminin uygulanması olarak devam edecektir.

\subsection{Weber Problemin'nin Weiszfeld Yöntemine Uygulanması}

Weber Problemi (WP), Alfred Weber tarafindan 1909 yılında oluşturulan ve lokasyon eniyileme amaçlı kullanılan bir yöneylem araştırmasıdır (Weber, 1929). Bu problem, temel olarak öklidyen uzunlukların ağırlıklı toplamlarını minimize ederek çözülmektedir (Tellier, 1972; Cooper ve Katz, 1981; Brimberg, 1995; Venceslau vd., 2016). Aşağıda WP'nin kısaca bir açıklaması gösterilmiştir.

$$
\min _{\bar{x}} \sum_{j=1}^{n} w_{j}\left\|\bar{x}-\bar{x}_{j}\right\|
$$

öyle ki, $\bar{x}=(x, y)$ ve, $\bar{x}_{j}=\left(x_{j}, y_{j}\right)$ 'dir. Buna ek olarak, $\overline{x_{j}}$ noktaları $E^{2}$ düzleminde noktalardır ve $w_{j}$ noktaların rakamsal önem ağırlıklarıdır. (3) numaralı eniyilemede, en uygun $\bar{x}$ konumu tespit edilmektedir.

Enrich Weiszfeld tarafindan 1937 yılında oluşturulan Weiszfeld metodu kullanılarak WP'i çözülebilmektedir (Weiszfeld, 1937; Eckhardt, 1980; Chen, 1984). Bu prosesi yapan yazılımlar piyasada yer almaktadır. LINGO bilgisayar programı bu çalışmadaki eniyilemeyi yapmak amacıyla kullanılmıştr, çünkü LINGO programı Weiszfeld algoritmasını kullanarak WP'nin sonucuna ulaşmaktadır (LINDO Systems Inc., 2017). Weiszfeld metodunu uygulayan LINGO programının bu çalışmadaki problemin çözümüne uygun olduğu düşünülmesinin nedeni Weiszfeld algoritmasının asıl amacı olan bir düzlemde öklidyen uzunlukları verilen ağırlıklı noktaların optimum lokasyonunu tespit etmesidir (Aftab, 2015). Bu tespiti, bütün ihtiyaç noktalarının ağırlık derecelerini tatmin edecek en uygun lokasyonu tahsis edinceye dek konum iterasyonlarını yaparak elde eder (Üster ve Love, 2000). Devam eden iterasyonların sonuç konumunu artık değiştirmediği görülünce iterasyonlar durur ve sonuç belirlenir.

Analiz kısmında belirtilen matematik problemi ve çözüm yöntemi bu çalışmadaki eniyileme yönteminin kullanılmasına yardımcı olacağı düşünülmüştür. Havalimanlarının konum ve önem ağırlık verileri elimizde mevcut olduğundan dolayı bu bölümde bahsedilen çözüm yönteminin çalışmamıza nasıl uygulandığını içermektedir. Uygulamanın açık formülasyonu şu şekildedir:

Değişkenler:

$\left(X_{\text {Iok},}, Y_{\text {lok }}\right)$ : Acil ihtiyaç duyulan hizmetin tedariki için en uygun yer olarak belirlenecek olan lokasyon

$n$ : Toplam havalimanı sayısı (bu çalışmada $n=55$ )

$\mathrm{i}=1,2, \ldots, \mathrm{n}: 1^{\prime}$ den n'e kadar havalimanları

$\left(X_{h i}, y_{h i}\right)$ : 1'den n'e kadar havalimanlarının koordinatları

$a_{\text {hi }} \quad:$ 1'den n'e kadar havalimanlarındaki toplam talep, hizmet verilen uçak adedi, (Not: Bu talep havalimanının tercih ağırlığını göstermektedir.)
$D_{i} \quad$ : Belirlenecek olan lokasyona, $\left(X_{\text {lok, }} Y_{\text {lok }}\right)$, öklidyen uzaklık. $D_{i}=\sqrt{\left(X_{l o k}-x_{h i}\right)^{2}+\left(Y_{l o k}-y_{h i}\right)^{2}}$

$a_{h i} D_{i} \quad$ : Belirlenecek olan lokasyona, $\left(X_{\text {Iok, }}, Y_{\text {lok }}\right)$, ağırlıklı öklidyen uzaklık. $a_{h i} D_{i}=a_{h i} \sqrt{\left(X_{l o k}-x_{h i}\right)^{2}+\left(Y_{l o k}-y_{h i}\right)^{2}}$

Buna göre

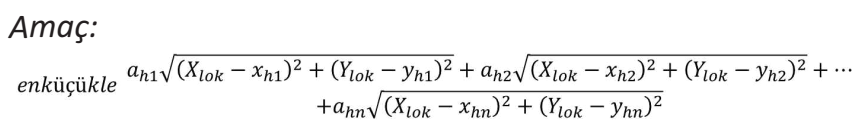

Amaç fonksiyonu düzenlenirse:

enküçükle $\sum_{i=1}^{n} a_{h i} D_{i}$

öyle ki, $\left(X_{\text {lok, }} Y_{\text {lok }}\right) \geq 0$.

Toplamda ülkemiz çapında 55 adet sivil havacılığa hizmet veren havalimanı bulunmaktadır (DHMi, 2017b). Bu araştırmada, bütün bu havalimanlarının 2016 yılı Kasım ayından 2017 yılı Ekim ayına kadar olan on iki aylık dönemde tüm uçak trafiği (iç hatlar ve dış hatlar olmak üzere) incelenerek havalimanını kullanan uçak sayıları ele alınmıştır. Örnek olarak görselleştirmek gerekirse, Tablo 1'de verileri kullanılan bazı havalimanlarının 2016 yılı Kasım ayından 2017 yılı Ekim ayına kadar olan on iki aylık süreç içerisindeki verilerinden bir miktarı gösterilmektedir.

Tablo 1. Havalimanlarına göre toplam uçak trafiği verilerinden bir örnek (DHMi, 2017a).

Table 1. Total of the airplane traffic data related to the airports (DHMi, 2017a).

\begin{tabular}{|c|c|c|c|c|c|c|c|}
\hline & \multicolumn{6}{|c|}{ Dönem } & \multirow{2}{*}{$\begin{array}{c}\text { On iki } \\
\text { Aylik } \\
\text { Ortalama }\end{array}$} \\
\hline $\begin{array}{l}\text { Havalimanlarından } \\
\text { Örnekler } \\
\end{array}$ & $\begin{array}{l}\text { Şubat } \\
2017\end{array}$ & $\begin{array}{l}\text { Mart } \\
2017\end{array}$ & $\begin{array}{l}\text { Nisan } \\
2017 \\
\end{array}$ & $\begin{array}{l}\text { Mayıs } \\
2017 \\
\end{array}$ & $\begin{array}{l}\text { Haziran } \\
2017\end{array}$ & $\begin{array}{c}\text { Temmuz } \\
2017\end{array}$ & \\
\hline istanbul Atatürk & 63.608 & 99.822 & 138.351 & 178.062 & 217.037 & 260.360 & 243.611 \\
\hline hha Gökçen & 31.931 & 49.256 & 66.976 & 85.686 & 104.511 & & 118.535 \\
\hline Ankara Es & 16.514 & 25.492 & 34.285 & 43.448 & 53.007 & 4.273 & \\
\hline izmir Adnan N & 12.447 & 19.181 & 26.236 & 33.706 & 1.432 & .423 & 6.568 \\
\hline & & 16.2 & 26.5 & & & & 73.084 \\
\hline Gazipaş & 404 & 679 & 131 & 1.805 & 2.544 & 3.406 & 3.098 \\
\hline & & & & & & & \\
\hline Muğla Milas Bodrum & 1.6 & 2.458 & 3.916 & 6.331 & 10.119 & 15.430 & 4.574 \\
\hline Adana & 7.332 & 11.660 & 15.342 & 18.795 & 2.518 & 6.671 & 5.268 \\
\hline Trabzon & 3.859 & 5.959 & 8.166 & 10.441 & 12.916 & 16.081 & 14.707 \\
\hline
\end{tabular}

Bilgisayar ortamında çözümleme için LINGO 17.0 programı tercih edilmiştir (LINDO Systems Inc., 2017). Programın deneme amaçlı olan kurulumu internet sitesinde ücretsiz olarak bulunmaktadır. Intel ${ }^{\circledR}$ Core $^{\mathrm{TM}}$ i7-2640M CPU @ 2.80GHz işlemcili, 8GB dâhili belleği olan 64-bit işletim sistemi özelliklerine sahip bir bilgisayarda kurulumu yapılan LINGO'da (4) numaralı amaç fonksiyonunun kodlaması yapılmıştir. Elde edilen bulgular ve değerlendirme bir sonraki bölümde ele alınmıştır.

\section{Bulgular ve Tartışma}

Kodlamanın LINGO 17.0'da çalışması bir saniyeden az bir süre olan 0,64 saniyede tamamlanarak sonuçlar elde edilmiştir. İngilizce olan programın sağladığı çıktılardan bir ekran görüntüsü alınarak Şekil 1'de gösterilmiştir. Toplam 78 iterasyon ile birlikte yapılan eniyileme sonucunda amaç fonksiyonunun sonucu 46309,50 olarak tespit edilmiş ve çözüme ulaşılmıştır. Ayrıca bu eniyilemenin verdiği lokasyon, bir başka deyişle $\left(X_{\text {lok }}, Y_{\text {lok }}\right)$ koordinatı (Şekil 1'de XX ve YY olarak görülebilir.), (0,7113269, 0,5338182 ) olarak bulunmuştur.

Sonuç lokasyonu olan $(0,7113269,0,5338182)$ koordinat harita 
üzerinde konumlandırıldığında, bu noktada herhangi bir havalimanının bulunmadığı gözlemlenmiştir. Şekil 2'de Google Maps (2018) yardımıyla gösterilen ideal havaalanı koordinatları $(0,7113269,0,5338182)$ olarak belirlenen lokasyonda görüldüğü üzere herhangi bir havalimanı mevcut değildir.

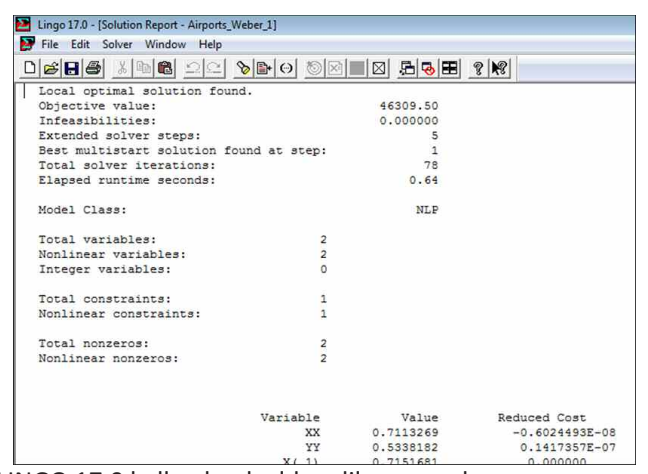

Şekil 1. LINGO 17.0 kullanılarak elde edilen sonuçlar.

Figure 1. Results assessed using LINGO 17.0.

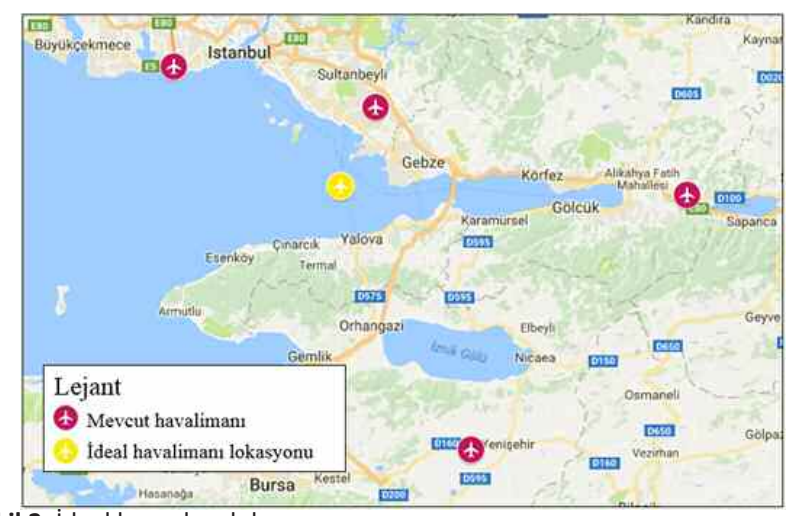

Şekil 2. Ideal havaalanı lokasyonu.

Figure 2. Ideal airport location.

Bu araştırmada, ülkedeki bütün havalimanlarına acil durumlarda $(0,7113269,0,5338182)$ lokasyonundan hizmet sağlanabileceği tespit edilmesine rağmen, bu konumda hâlihazırda bir havalimanı bulunmadığı için, bu koordinata en yakın havalimanının bahse konu acil durumlarda hizmet verebileceği değerlendirilmektedir. Bu bağlamda, eniyileme sonucunda elde edilen koordinata en yakın havalimanının saptanması için analitik geometrideki iki nokta arasındaki uzaklık bulma yöntemi kullanılarak, sonuç lokasyonuna en yakın havalimanı tespit edil- miştir. Ayrıca, amaç fonksiyonunda belirtildiği üzere, havalimanlarını kullanan uçak adetleri -bir başka deyişle iniş ve kalkış yapan uçak sayıları- ile birlikte havalimanları arasındaki ilişkiler mesafe incelenerek sonuca varılmıştır. Her ne kadar Türkiye'nin doğudan batiya doğru uzanan coğrafi şekli gereği havalimanları arası uzaklıklar önerilmesi istenen havaalanının yerini tespitte önem teşkil etse de havalimanlarındaki hava trafiği yoğunluğu bu çalışmadaki analizi büyük oranda etkilemiştir. Ancak, kullanıldığı üzere, havalimanları arasındaki mesafe cinsinden ilişkiler de önerilmesi gereken havalimanının ortaya çıkarılmasında büyük rol oynamıştr. Mesela sadece hava trafiğinin kullanıldığı bir optimizasyon yapılsaydı, belirlenen lokasyonun iniş ve kalkışın en çok yapıldığı İstanbul Atatürk Havalimanı (Tablo 1) tarafina daha fazla yönlenmesi muhtemel olabilirdi. Bu yüzdendir ki, Şekil 3'te görüldüğü üzere, önerilen mevcut havalimanı olan Sabiha Gökçen Havalimanı'nın doğusunda veya Türkiye'nin doğu kesimlerinde birçok havalimanı mevcut olmasına ve bunların mesafelerine rağmen hava trafiği kıstası lokasyon belirlemede çok etkin bir rol oynamaktadır.

Çalışmalar doğrultusunda, talep edilen acil hizmet veya hizmetlerin tedariki için gereken personel, donanım ve uçak ile ilgili komponentlerin İstanbul Sabiha Gökçen Havalimanı'nın konumu gereğince bu havalimanında konumlandırılması gerektiği saptanmıştır.

\section{Sonuç}

Türkiye sivil havacılığa yaptı̆̆ son yıllardaki yatırımlarla bu alanda çok büyük bir büyüme kaydetmiştir. Büyümeye verilen değer günden güne artmakta ve Türkiye'deki sivil havacılığın gelişmesindeki ivme artarak devam etmektedir. Hızlı gelişim, altyapının da aynı ivme ile gelişmesini gerektirmektedir. Örneğin, uçağın havalanmasından önce yapılan kontrollerde acil müdahale gerektiren mekanik bir parça konusunda ivedi bakım personeli veya yedek parça ihtiyacı doğabilir. Bu ihtiyacın tedariki bir başka havalimanından gelmesi gerekebilir. Bu önemli hususa dayanarak, beklenmedik durumlarda bakım personeli ve yedek parça hizmetlerinin bir diğer havalimanından tedariki için Türkiye sınırları dâhilinde en kullanılabilir havalimanının tespiti, Weber problemine adapte edilip Weizsfeld yöntemi doğrultusunda bu çalışmada gerçekleştirilmiştir. Elde edilen

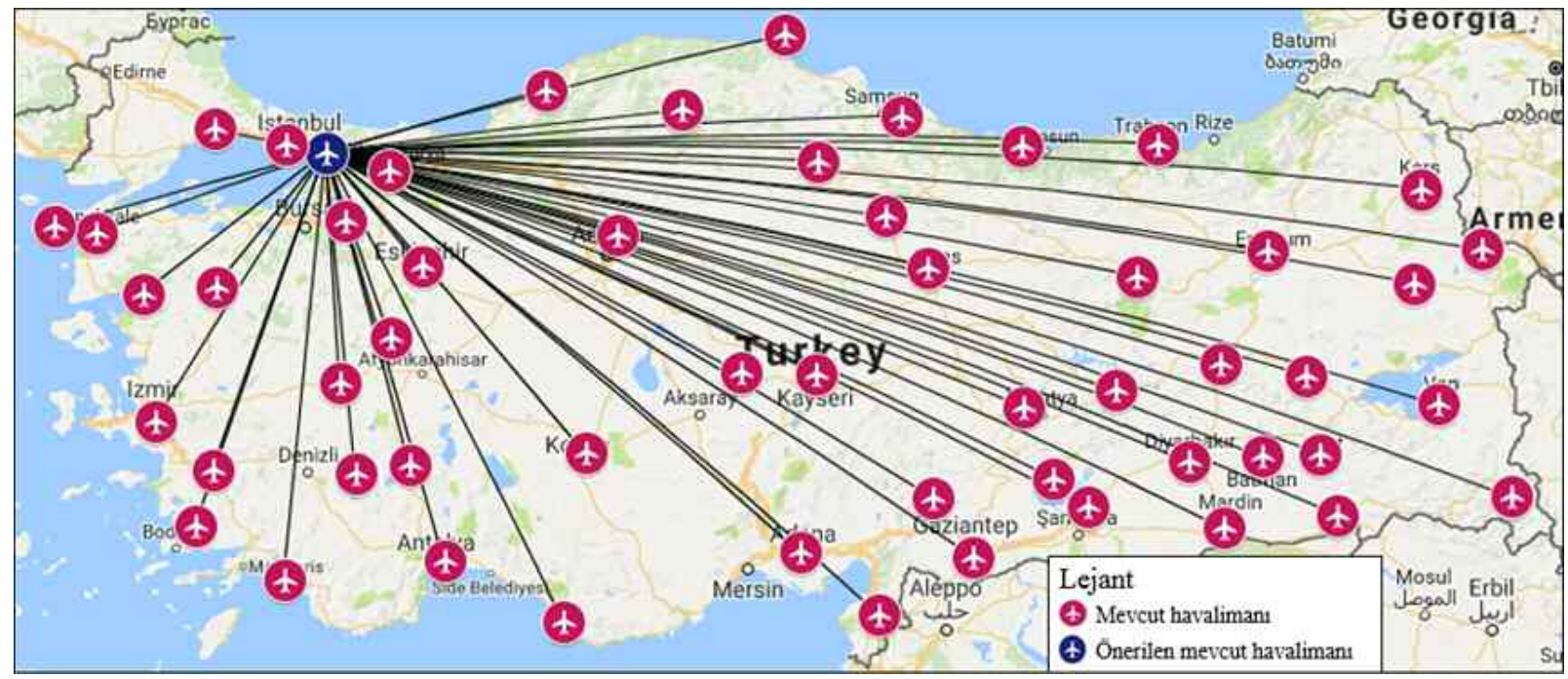

Şekil 3. Sabiha Gökçen Havalimanı’nın diğer havalimanlarına olan mesafe cinsinden ilişkisi.

Figure 3. The relationship between Sabiha Gökçen Airport and the other airports according to the distance. 
bulgular şunu göstermektedir ki, Türkiye'de bir tane havalimanı seçilmesi gerektiği takdirde, İstanbul Sabiha Gökçen Havalimanı́nın Türkiye çapına servis sağlanması ve acil durumlarda talep edilenin karşılanması açısından en kullanılabilir havalimanı olduğu değerlendirilmektedir. Böylelikle bu çalışma neticesinde, acil gereken hizmetler karşısında zaman ve gelir kaybının azaltılması, yolcu memnuniyetinin arttırılması gibi hedefler gözetilirken havayolu kazası riskinin de en alt seviyelerde tutulması konusunda ilerleme kaydedilecektir.

İstanbul'da bulunan ve halihazırda Türkiye'nin en donanımlı havalimanı olan Atatürk Havalimanı'nın bu makale sonucunda önerilmemesinin gerekçesi, yapılan analizin kapsamında havaalanlar arası mesafe yönünden ilişkilerin yanı sıra iniş-kalkış yapan uçak adetlerinin dikkate alınmasıdır. Mevcut havaalanlarındaki teknik donanımlar incelemeye dâhil edildiği takdirde göstergenin Atatürk Havalimanı'na doğru kayması kuvvetle muhtemeldir. Ancak, Weizsfeld yöntemi kullanılarak önerilen İstanbul Sabiha Gökçen Havalimanı'nda da donanımların hazır hale getirilmesi önerilmektedir.

Yakın bir zamanda hizmete girmesi planlanan ve dünyanın en gelişmiş teknolojisine sahip olacağı ifade edilen İstanbul 3. Havalimanı bu çalışmanın kapsamı dışında tutulmuştur. Ancak, hizmete girdiğinde -bu çalışmada olduğu gibi on iki aylık veriler elde edilir edilmez- analizdeki yerini alması düşünülmektedir. Ayrıca İstanbul 3. Havalimanı'nın İstanbul'da mevcut olan diğer iki büyük havalimanının hava trafiğini paylaşacağı veya daha büyük oranda trafik yükü üstleneceği ifade edildiğinden dolayı etrafindaki mevcut iniş-kalkış miktarlarını değiştirebileceği ön görülmektedir. Bu kapsamda, İstanbul 3. Havalimanı'nın bu çaIışmadaki bulgulara olan etkisi veriler elde edildiği takdirde açıkça görülecektir.

İdeal lokasyonda bir havalimanı olmadığı için, önerilen Sabiha Gökçen Havalimanı kendisine göreceli olarak uzak olan örneğin Kars Harakani Havalimanı gibi havaalanlarına etkili bir hizmet sağlaması bu çalışmada izlenen Weizsfeld yöntemi çerçevesine göre -hem hizmetin sağlanacağı havaalanında iniş ve kalkış miktarları hem de havalimanları arası mesafeler gözetilerek- geçerli olduğu değerlendirilmektedir. Bunlara ek olarak, acil bir durumda hizmet sağlanması için bölgesel ölçekte donanımlı birden fazla havalimanı da önerilebilir. Bu tür bir çıktıyı eldeki verileri kullanarak gerçekleştirmenin bir yöntemi ise havalimanlarını kümeleme yaparak veya gruplandırarak değerlendirmek olabilir. Kısaca açıklamak gerekirse çeşitli yöntemler kullanılarak havalimanlarını sadece aralarındaki mesafeleri dikkate alarak küme küme ayırdıktan sonra kümelerin kendi içinde ayrı ayrı Weizsfeld yöntemi kullanılarak sadece kendi bölgesine hizmet vermesi beklenen havaalanlar keşfedilebilir. Bu öneri, yukarıda yapılan çalışmanın bir devamı niteliğinde araştırılması planlanmaktadır.

\section{Katkı Belirtme}

Akademik analiz amaçlı kullanılan hava trafik araştırma verilerinin internet üzerinden temin edildiği Devlet Hava Meydanları İşletmesi'ne teşekkür ederim.

\section{Kaynakça}

Aftab, K., Hartley, R., Trumpf, J. (2015). Generalized Weiszfeld Algorithms for Lq Optimization. IEEE Transactions on Pattern Analysis and Machine Intelligence, 37(4): 728-745.

Airport Haber (2017). <http://www.airporthaber.com/havacilik-haberleri/sivil-havaciligin-sorunlari-ve-cozum-onerileri25357h.html>. Son erişim 16 Kasım 2017.

Brimberg, J. (1995). The Fermat-Weber Location Problem Revisited. Mathematical Programming, 71(1): 71-76.

Chen, R. (1984). Location Problems with Costs Being Sums of Powers of Euclidean Distances. Computers and Operations Research, 11(3): 285-294.

Cooper, L., Katz, I.N. (1981). The Weber Problem Revisited. Computers and Mathematics with Applications, 7(3): 225-234.

DHMi (Devlet Hava Meydanları İşletmesi Genel Müdürlüğü) (2017a). <http://www.dhmi.gov.tr/istatistik.aspx>. Son erişim 15 Kasım 2017.

DHMi (Devlet Hava Meydanları İşletmesi Genel Müdürlüğü) (2017b). <http://www.dhmi.gov.tr/havaalanlari.aspx>. Son erişim 16 Kasım 2017.

Eckhardt, U. (1980). Weber's Problem and Weiszfeld's Algorithm in General Spaces. Mathematical Programming, 18(1): 186-196.

Google Maps (2018). <https://maps.google.com>. Son erişim 19 Mart 2018.

LINDO Systems Inc. (2017). <http://www.lindo.com/index.php/products/lingo-and-optimization-modeling>. Son erişim $17 \mathrm{Kasım}$ 2017.

Özdoğan, M., Tosun, N., Ağalar F., Eryılmaz, M., Aydınuraz, K. (2005). "An Evaluation of Civilian Aviation Accidents in Turkey from 1955 to 2004", Turkish Journal of Trauma and Emergency Surgery, 11(4): 318-323.

SHGM (Sivil Havacılık Genel Müdürlüğü) (2016). <http://web.shgm.gov.tr/documents/sivilhavacilik/files/pdf/kurumsal/raporlar/2016_faaliyet_raporu.pdf>. Son erişim 30 Kasım 2017.

Snyder, J.P. (1987). Map Projections - A Working Manual. U.S. Geological Survey Professional Paper 1395, United States Government Printing Office, Washington.

Tellier, L.N. (1972). The Weber Problem: Solution and Interpolation. Geographical Analysis, 4(3): 215-233.

Uçak-Havacılık-Uzay Mühendisliği Meslek Dalı Ana Komisyonu (2016). İstatistiklerle Hava Taşımacılığı Kazaları. Mühendis ve Makina, 48(566): 13-19.

Üster, H., Love R.F. (2000). The Convergence of the Weiszfeld Algorithm. Computers and Mathematics with Applications, 40(4): 443451.

Venceslau, H.M., Karam Venceslau, M.B., Xavier, A.E., Maculan, N. (2016). A Geometric Perspective of the Weiszfeld Algorithm for Solving the Fermat-Weber Problem. RAIRO -Operations Research, 50(1): 157-173.

Weber, A. (1929). Über den Standort des Industrien. "Alfred Weber's Theory of the Location of Industries", C.J. Friedrich (Tercüman). University of Chicago Press, Chicago, IL, USA.

Weiszfeld, E. (1937). Sur le point pour lequal la somme des distances de $\mathrm{n}$ pointes donnes est minimum. The Tohoku Mathematical Journal, 43: 335-386. 
